\title{
O cálculo de Maria: contribuições de um jogo interdisciplinar para o desenvolvimento da cidadania
}

Céres de Oliveira Jendreieck ceres oi@yahool.com.br orcid.org/0000-0001-9733-4581 Prefeitura Municipal de Curitiba, Curitiba, Paraná, Brasil

\section{Ettiène Guérios}

ettiene@ufpr.b

orcid.org/0000-0001-5451-9957

Universidade Federal do Paraná (UFPR), Curitiba, Paraná, Brasil

\begin{abstract}
RESUMO
O presente artigo tem por finalidade apresentar um recorte de uma pesquisa que investigou contribuições que um jogo educativo interdisciplinar proporcionou para o desenvolvimento de habilidades das disciplinas de matemática e geografia de alunos do 3 o ano do Ensino Fundamental. Os principais referenciais teóricos utilizados foram Grando (2000, 2004), Machado $(2001,2006)$ e Moura $(1992,2010)$ no que tange a dimensão lúdica. A pesquisa teve abordagem qualitativa e de intervenção. Os participantes foram 8 alunos matriculados no 3 o ano do Ensino Fundamental. As pesquisadoras criaram um jogo interdisciplinar que foi validado por uma equipe de profissionais da educação. Para a coleta de dados realizouse uma atividade inicial, acompanhada de cinco partidas seguidas de cinco atividades diferentes com foco na resolução de situações-problema advindas do jogo e uma atividade final. Foi realizada uma observação sistemática in loco com posterior produção de narrativas, filmagem das partidas e das atividades após o jogo e registros das resoluções das atividades inicial e final. Para análise foi criado um método próprio para esta pesquisa, realizando-se uma triangulação dos instrumentos. Neste artigo será apresentada uma fração dos resultados obtidos e suas discussões. Maria é o nome fictício de uma das participantes do jogo sendo a sua participação o foco desse artigo. Conclui-se que o jogo, com sua característica interdisciplinar, pode auxiliar professores nas aulas de matemática e de geografia, além de aliar aprendizagem matemática à aprendizagem de valores cidadãos, constituindo-se um produtivo recurso Educativo.
\end{abstract}

PALAVRAS-CHAVE: Interdisciplinaridade. Jogo. Ensino de matemática. Cidadania e matemática. 


\section{INTRODUÇÃO}

O presente artigo é proveniente de uma pesquisa de mestrado realizada no Programa de Pós-graduação em Educação: Teoria e Prática de Ensino da Universidade Federal do Paraná. O objetivo da pesquisa foi identificar possíveis contribuições que um jogo educativo interdisciplinar pode proporcionar para o desenvolvimento de habilidades das disciplinas de matemática e geografia em alunos de 30 ano do Ensino Fundamental de uma escola municipal de Curitiba.

Durante o desenvolvimento da pesquisa, um dos aspectos que mais chamou nossa atenção foi a vivência de valores e cidadania na experiência com o jogo em atividades voltadas ao desenvolvimento de habilidades em matemática e em geografia. Por isso, no presente artigo apresentamos o que identificamos acerca de contribuições do jogo para a aprendizagem da cidadania e vivência de liberdade, focalizando as análises especificamente na experiência interdisciplinar vivenciada por uma das participantes, que recebeu o nome fictício de Maria. Iniciamos abordando brevemente sobre nosso entendimento sobre cidadania e liberdade e o papel da escola a partir deste entendimento.

Adotamos como pressuposto que os termos "direitos" e "deveres" constituem um binômio indissolúvel para a aprendizagem da cidadania e que nos anos iniciais do Ensino Fundamental as crianças podem vivenciar situações que apontem para esta aprendizagem. Nesse sentido, nos aproximamos de Machado (2001) para quem a ideia de cidadania não pode ficar restrita a ideia de ter direitos, pois significaria uma "limitação da formação do cidadão", restringindo seu significado político e filosófico. Ele defende que "mesmo em países onde os direitos humanos não costumam ser violados, a necessidade da formação do cidadão permanece viva, relacionando-se com a semeadura de valores e articulação entre os projetos individuais e coletivos". (MACHADO, 2001, p. 95)

Concordando com Machado (2001), entendemos que ser cidadão envolve as questões relativas aos direitos humanos e também aos direitos políticos. Isto quer dizer que além de preocupar-se com seus próprios direitos, o cidadão preocupa-se com as decisões coletivas e age em benefício deste coletivo. Para ser realmente cidadão, é necessário ter vontade, capacidade e possibilidade de envolver-se com decisões políticas.

Machado (2001, p. 106) propõe uma noção de cidadania que "transcenda o estatuto de uma postulação de direitos humanos" e inclua "a participação ativa no tecido social, assumindo responsabilidades relativamente aos interesses e ao destino de toda a coletividade".

\footnotetext{
Múltiplos são os instrumentos para realização plena dessa cidadania ativa: a "alfabetização" relativamente aos dois sistemas básicos de representação da realidade - a língua materna e a matemática, condição de possibilidade do conhecimento em todas as áreas; a participação do processo político, incluindo-se o direito de votar e ser votado; a participação da vida econômica, incluindo-se o desempenho de uma atividade produtiva e o pagamento de impostos; e, naturalmente, o conhecimento de todos os direitos a que todo ser humano faz jus pelo simples fato de estar vivo. (Idem, p.107).
}

Neste extrato, Machado nos mostra a importância da escola como partícipe na formação do cidadão, pois é ela que proporciona institucionalmente a aprendizagem da língua e da matemática, assim como, conhecimento dos direitos, 
compreensão da vida política e condições para o desempenho de atividade econômica.

No entanto, segundo nossa compreensão, isto não basta para ser cidadão. 0 cidadão precisa, também, ser dotado de liberdade. Morin diz que liberdade

É a possibilidade de escolha entre diversas alternativas. Bem, a liberdade supõe duas condições. Em primeiro lugar, uma condição interna, a capacidade cerebral, mental, intelectual necessária para considerar uma situação e poder estabelecer suas escolhas, suas apostas. Em segundo lugar, as condições externas nas quais essas escolhas são possíveis. [...] podemos, assim, observar diferentes tipos, diferentes graus de liberdade, segundo tenhamos possibilidades de escolha mais ou menos amplas e mais ou menos básicas, que permitam gozar de maior grau de liberdade. (MORIN, 1996, p. 53).

Consideramos que o papel da escola na formação do cidadão é também proporcionar estas condições para a liberdade. A primeira, desenvolvendo capacidades cerebrais, mentais e intelectuais, por meio da aprendizagem de conteúdos e habilidades de resolução de situações-problema utilizando pensamento interdisciplinar. Ou seja, proporcionando as condições intelectuais necessárias para a compreensão e resolução das situações que se lhes apresentem. E a segunda, proporcionando espaços de criação, de cidadania e situações em que os alunos possam exercer sua liberdade de escolha.

Compreendemos o jogo, portanto, como um instrumento que pode ser útil para proporcionar estas condições de liberdade e cidadania, pois desenvolve capacidades cerebrais, mentais e intelectuais pelo uso da razão para criação de estratégias para solucionar situações do jogo buscando vencer.

Além disso, o jogo é um espaço de liberdade de escolha, apesar de ser necessário seguir regras quando se está jogando. $O$ jogo permite a tomada de decisão a cada jogada, pois o jogador faz uma escolha ao executar uma ou outra ação. É possível também avaliar os resultados dessas escolhas e, se desejar, mudar de estratégia na sequência das jogadas.

O jogo também simula a vida social, na medida em que se constrói na relação entre os jogadores. Essa relação pode ser ora competitiva, ora colaborativa. Mas é também um compartilhar de objetivos, ideias, ações, prazer, criação, emoção, desenvolvimento, superação (de si mesmo e do outro).

No jogo, as relações entre os participantes são permeadas por valores, como respeito, competitividade, colaboração. E banhadas de emoções, como desejo de vencer, ansiedade, prazer e desprazer. Em meio a esses valores e emoções o jogo acontece numa situação de liberdade na qual é possível criação e escolha entre diversas possibilidades para tomada de decisão. Assim o jogo permite ao aluno vivenciar uma situação de liberdade, limitada pelas suas regras e pela ação dos adversários. É também uma situação de responsabilidade, pois as decisões no jogo terão consequências, como a vitória ou a derrota.

Partindo do que foi colocado até aqui, podemos considerar que o jogo tem um papel importante na formação individual e na vida social dos alunos, consequentemente, na formação do cidadão. Ao jogar, a pessoa se humaniza, exercendo a liberdade presente nas possibilidades do jogo (de criação, de 
invenção, de estratégias) e a limitação imposta pelas regras, que precisam ser aceitas e respeitadas, assim, simulando também a liberdade na vida real.

Considerando o jogo como um instrumento pedagógico interessante para a formação do cidadão, tivemos a ideia de criar um jogo educativo que auxiliasse no desenvolvimento de habilidades das disciplinas de geografia e matemática de alunos do Ensino Fundamental, ao mesmo tempo em que se constituísse em possibilidade de desenvolvimento de valores para o exercício da cidadania. Após sua criação, o implementamos em turmas do 3 o ano do Ensino Fundamental e passamos a investigar suas possíveis contribuições para o desenvolvimento de habilidades em disciplinas de matemática e geografia.

A seguir, apresentamos o método utilizado nesta pesquisa. No subitem "O jogo", fazemos uma breve apresentação do jogo e seus objetivos educativos. No subitem "Resultados e discussão", apresentamos um extrato dos dados coletados e suas análises. Nas "Considerações Finais" buscamos demonstrar o que nos propusemos neste artigo: as contribuições do referido jogo educativo interdisciplinar para a vivência de valores e cidadania na experiência com atividades voltadas ao desenvolvimento de habilidades em matemática e em geografia próprias do 3o ano do Ensino Fundamental.

\section{MÉTODO DE PESQUISA}

A pesquisa foi conduzida a partir do desenvolvimento de ações interventivas produtoras de mudanças no ambiente de sala de aula, mudanças a serem então submetidas à análise. Assim, a pesquisa se amparou em abordagem qualitativa e de cunho interventivo. Damiani (2012) explica que as pesquisas de intervenção são pesquisas aplicadas que partem de uma intenção de mudança ou inovação que se realiza por meio de práticas a serem analisadas. Estas pesquisas trabalham com dados criados e envolvem uma avaliação rigorosa e sistemática dos efeitos das práticas, ou seja, indo além das descrições e chegando numa análise mais aprofundada. Elas têm como característica buscar "contribuir para o avanço do conhecimento sobre os processos de ensino/aprendizagem neles envolvidos". (DAMIANI, 2012, p. 3)

Nesta pesquisa, as práticas de intervenção foram as partidas do jogo, as atividades propostas após as partidas e a ação didática, ensinando aos participantes as regras do jogo e como jogar, incentivando-os a pensar sobre as opções de jogadas, a criar estratégias e também a auxiliar na identificação e correção de erros durante o jogo.

Os participantes da pesquisa foram 8 alunos matriculados no 3 o ano do Ensino Fundamental de uma escola municipal de Curitiba que foram organizados em dois grupos para a realização das partidas do jogo.

O processo de coleta de dados foi realizado por meio de observação sistemática in loco registrada em diário, filmagem das partidas e de atividades após cada partida e registros de uma, atividade inicial e outra final que tiveram a finalidade de produzir dados norteadores para a análise do conjunto dos demais dados. 
Com base no referencial teórico e no objetivo da pesquisa, criamos focos prévios de investigação, que foram: interdisciplinaridade entre geografia e matemática; cidadania; estratégias cognitivas; resolução de problemas de jogo; antecipação no jogo.

Para análise, foi realizada uma triangulação entre os dados provenientes dos diferentes instrumentos. Os focos de investigação permeiam as reflexões de uma maneira integrada.

Esta pesquisa foi aprovada pelo Comitê de Ética em Pesquisa da Universidade Federal do Paraná em 03 de junho de 2016, através do parecer no 1.573.515.

\section{O JOGO}

Trata-se de um jogo de tabuleiro que representa ruas de uma cidade fictícia. Nos pontos extremos do tabuleiro estão as saídas Norte, Sul, Leste e Oeste representando os pontos cardeais. No tabuleiro há uma bússola e pontos de referência. Compõem o material do jogo: um dado cujos lados são quantidades, um dado cujos lados são orientações para movimentações no tabuleiro a partir de noções topológicas e lateralidade, quatro carrinhos e oitenta e quatro "cartas estrelas". Para iniciar o jogo, os jogadores devem usar a bússola para alinhar o tabuleiro na direção Norte-Sul e organizar as cartas estrela de tal modo que cartas iguais fiquem em uma mesma pilha, e estas fiquem lado a lado. $O$ objetivo do jogo é andar pelas ruas do tabuleiro com o carrinho e entrar no local denominado Estacionamento, passando, no trajeto, por diferentes pontos de referência. Ao passar por cada ponto de referência o jogador ganha uma carta estrela. Para vencer o jogo é necessário coletar 10 cartas diferentes e então entrar no estacionamento. (JENDREIECK, 2017).

Para jogar, cada aluno, na sua vez, lançará o dado das quantidades. Este dado indicará o número de casas que devem ser percorridos pelas ruas do tabuleiro. É permitido andar apenas sobre as ruas e na rotatória. $\mathrm{O}$ jogador poderá escolher a direção que deseja seguir com a quantidade de casas que obteve com o dado. 0 fato de precisar de 10 cartas estrela de referência para entrar no Estacionamento o obriga a criar estratégias para escolher os caminhos que vai seguir com o número de casas que poderá se deslocar no tabuleiro com o resultado do dado de quantidades. Os jogadores terão que criar estratégias para se deslocarem no tabuleiro, visto que podem chegar ao estacionamento sem terem obtido as dez cartas estrelas diferentes para poderem entrar, o que os obrigará a permanecer jogando até obtê-las, para então se dirigirem para a entrada do estacionamento, administrando os resultados do dado de quantidades. Ou podem obter as 10 cartas e estarem longe do estacionamento. Nesse caso, devem continuar jogando, até conseguir entrar no estacionamento.

Durante o percurso, cada aluno deverá estar atento às indicações do tabuleiro. Quando passar por algum símbolo ou sinal de trânsito ou trecho da rua pintado de cor diferente, deverá verificar na Legenda a orientação a ser seguida.

Como dissemos, este jogo educativo foi criado com objetivo de auxiliar no desenvolvimento de habilidades das disciplinas de geografia e matemática. As habilidades pretendidas com o jogo foram: localizar-se no espaço, utilizar noções topológicas, utilizar noções de lateralidade, compreender representações de 
espaços urbanos, usar adequadamente a bússola, movimentar-se respeitando regras de organização do espaço, usar a Rosa dos Ventos e os pontos cardeais, usar legenda, usar cálculo mental e outras estratégias de resolução dos problemas matemáticos. As referências para a definição por estas habilidades foram os Cadernos de Alfabetização Matemática do PNAIC (BRASIL, 2014), o Plano Curricular Preliminar de Curitiba (CURITIBA, 2016c), vigente durante o período de criação do jogo, e o documento "Elementos Conceituais e Metodológicos para a Definição dos Direitos de Aprendizagem e Desenvolvimento do Ciclo de Alfabetização (1으, 2o e 3o anos) do Ensino Fundamental" (BRASIL, 2012).

\section{RESULTADOS E DISCUSSÃO}

Neste subitem, nos detemos a apresentar movimentos de aprendizagem de um dos participantes da pesquisa. "Maria" é a participante protagonista. "Thomas" e "Carla" são participantes coadjuvantes. A pesquisadora que aplicou a intervenção é representada pelo pronome pessoal do caso reto da primeira pessoa do singular, "Eu". Apresentamos em quadros algumas descrições e diálogos.

No decorrer das partidas os alunos colaboravam uns com os outros. Todos aprendiam nessa interação permanente e com a ação didática da pesquisadora. Olhemos para Maria em momentos específicos por meio de trechos do diário da pesquisadora durante a intervenção com o jogo educativo e de episódios das partidas.

\section{Quadro 1 - Trecho do diário}

Iniciamos pelo momento em que perguntei "No Pare Roxo, o que tem que fazer, Maria?" Então ela pegou a legenda. Em seguida percebi que ela contou errado a quantidade de quadrados e solicitei que ela refizesse a contagem.

Fonte: JENDREIECK, 2017.

Contar errado não significa que Maria não tenha a habilidade de contar, significa que a habilidade de contar está em desenvolvimento e nesse processo, ora acerta, ora erra. Quanto mais ela desenvolver esta habilidade maior será a quantidade de acertos e menor a quantidade de erros. Portanto, as situações que envolvem a contagem no jogo contribuem para o desenvolvimento da habilidade de contar e outras habilidades na forma de um exercício por meio do qual, repetindo-se o uso dessas habilidades, o aluno as aprimora.

O jogo criado também apresenta oportunidades para a ação da didática da pesquisadora, conforme o episódio a seguir.

Quadro 2 - Episódio da primeira partida

Thomas estava na Via Rápida e tirou 4. Ele andou quatro e parou. Pediu uma carta para Carla. Enquanto isso eu disse "Lembre-se que é o dobro que você tem que andar!"

Então Maria disse "Mais dois, Thomas!"

Ele não andou. Maria disse novamente "Mais dois, Thomas! É o dobro!"

Eu falei "Maria, lembre-se que dobro não é mais dois, é duas vezes a mesma quantidade. Então se era 4..." e não terminei a frase esperando que um deles fizesse o cálculo e terminasse. 
Thomas disse "8" e andou com seu carrinho. Maria exclamou "Ah é!"

Na rodada seguinte ele continuava na Via Rápida. Tirou 3 no dado e falou "3! Então vou ter que andar 6!"

Alguns momentos mais tarde Maria estava no Pare Vermelho, tirou 1 no dado e por isso acabou tendo que entrar na Via Rápida. Na rodada seguinte tirou 6 e leu a legenda. Expliquei que ela precisava andar o dobro de 6. Perguntei "O que é dobro? Você sabe?"

Ela respondeu perguntando "Andar mais 1?"

Eu disse "Não. É como se você tivesse jogado duas vezes o seis, tá?"

Ela tentou calcular e disse "Eu não lembro quanto dá."

Perguntei “De que jeito você pode descobrir, então?"

Ela respondeu "Não sei."

Expliquei "O dobro de 6 é duas vezes o número 6. Como é que a gente faz esse cálculo?" Ela respondeu perguntando "6 mais 6?"

Respondi "Sim"

Então ela perguntou "6 + 6 dá 8?"

Eu disse "Você pode contar nos dedos, ou contar no dado e mais nos dedos."

Então ela colocou 6 nos dedos e contou duas vezes, respondendo "12."

Fonte: JENDREIECK, 2017.

Neste episódio, o jogo proporciona, por meio da ludicidade, uma situaçãoproblema que, para sua resolução, é necessário realizar o cálculo do dobro. Maria está acompanhando a jogada de Thomas e, enquanto tenta ajudá-lo, comete um erro quando diz "Mais 2, Thomas!" e acrescenta "Mais 2! É o dobro!" Nesta fala ela apresenta um problema com o conceito de dobro, pois ela pensa que dobro significa adição de dois. Para Maria o dobro de 4 é resultado da operação 4+2.

Essa situação, que surgiu por meio do jogo, gerou oportunidade para a ação didática da pesquisadora, que disse: "Maria, lembre-se que dobro não é mais dois, é duas vezes a mesma quantidade. Então se era quatro..." E, nessa ação didática, falou o conceito de dobro sem dar a resposta e sim oportunizando que Maria ou outro participante realizassem o cálculo correto.

Imediatamente Thomas completou dizendo " 8 ". Sua resposta rápida e sem utilização de contagem demonstra que ele realizou o cálculo mentalmente.

A importância da habilidade de cálculo mental é apontada por vários autores
(Parra, 1996; Hope, 1986; Mendonça, Lellis, 1989; Taton apud Udina Abelló,
1992) como sendo necessária para uma significativa compreensão do número
e de suas propriedades (domínio estrutural numérico) estabelecimento de
estimativas e para o uso prático nas atividades cotidianas. Além disso, a
habilidade com cálculo mental pode fornecer notável contribuição à
aprendizagem de conceitos matemáticos (relações / operações /
regularidades / álgebra / proporcionalidade) e ao desenvolvimento da
aritmética. (GRANDO, 2004, p.39-40).

Concordamos com Grando (2004) quando defende a importância do cálculo 
autonomia no raciocínio matemático, uma vez que ultrapassa o algoritmo ensinado comumente na escola e permite solucionar problemas de maneira criativa.

Alguns momentos mais tarde, Maria entrou na Via Rápida, então jogou o dado e tirou 6. Ela precisava consultar a legenda para saber qual a orientação para andar na Via Rápida. Esta habilidade (de reconhecer e utilizar símbolos na representação e organização do espaço) está prevista no Currículo do Ensino Fundamental de Curitiba (2016), na forma de um dos objetivos da disciplina de Geografia.

Lendo a legenda, Maria soube que seria necessário andar o dobro do valor retirado no dado. Maria, após a situação do erro anterior, percebeu que dobro não é adição de dois, porém ainda não compreendeu o que é dobro. Ela arrisca respondendo com uma pergunta "Andar mais um?".

Surge novamente a oportunidade da ação didática. A pesquisadora buscou ajudá-la a compreender o conceito de dobro e deixou que ela realizasse o cálculo dizendo: "É como se você tivesse jogado duas vezes o seis, tá?". Ela, por ainda não compreender, disse que não se lembrava. A pesquisadora tentou explicar novamente dizendo: "O dobro de seis é duas vezes o número seis. Como a gente faz esse cálculo?"

Então Maria pareceu ter compreendido o conceito e uma forma de calcular o dobro, então respondeu perguntando "6 mais 6 ?" $E$, após a confirmação ela tenta uma resposta dizendo "6 mais 6 dá 8?"

Questionamo-nos sobre o porquê de Maria dizer isso se ela tem condições de realizar esse cálculo contando nos dedos ou de outras formas. Pensamos que ela pode ter dado uma resposta qualquer para sair rápido da situação ou pode ter ficado com vergonha de contar nos dedos já que seus colegas realizam cálculo mental constantemente, ou ainda, que por ela não compreender o cálculo mental, acha que seus colegas acertam arriscando resultados. Após essa resposta de Maria a pesquisadora percebeu que teria que dizer a ela como realizar o cálculo e então explicou: "Você pode contar nos dedos ou no dado e mais nos dedos." Ela colocou 6 nos dedos e contou duas vezes, chegando ao resultado 12 .

Nas intervenções com Maria e com outros participantes a pesquisadora procurou agir por meio de questionamentos buscando não anular a ação cognitiva da criança, mas sim incentivá-la.

A habilidade de resolver problemas realizando cálculos está contemplada no Currículo do Ensino Fundamental de Curitiba na forma de um dos objetivos em Matemática: "Resolver e elaborar problemas que envolvam situações aditivas e multiplicativas." (CURITIBA, 2016a, p. 36).

A dificuldade de Maria com as habilidades de Geografia e Matemática é perceptível quando Maria tenta copiar as respostas de Thomas na atividade inicial. Além disso, Maria confundia seu carrinho com o dos colegas e se esquecia de algumas regras. Numa das partidas ela estava ganhando e não sabia. Ela já tinha 10 cartas, podia entrar no estacionamento e não entrou. A pesquisadora teve que orientá-la a entrar.

Tais dificuldades são evidenciadas durante as partidas do jogo e podem ser percebidas como no trecho a seguir, retirado da terceira partida: 
Quadro 3 - Trecho do diário

Maria ainda esquecia algumas regras e, quando os colegas estavam distraídos e não Ihe ajudaram eu perguntei "No Pare Roxo, o que tem que fazer, Maria?" Então ela pegou a legenda. Em seguida percebi que ela contou errado a quantidade de quadrados e solicitei que ela refizesse a contagem.

Fonte: JENDREIECK, 2017.

No entanto, um movimento de superação de algumas dificuldades pode ser reconhecido por meio das narrativas do diário quando, nas partidas finais, ela parou de confundir seu carrinho com o dos colegas (o que foi percebido e comentado por Carla), mostrou opções de trajetos para os colegas e realizou cálculos com mais sucesso.

Apresentamos a seguir outros episódios em que Maria precisou realizar cálculos.

\section{Quadro 4 - Episódio da primeira partida}

Maria estava no Pare Roxo. Ela tirou 4 e leu a legenda em voz baixa. Pegou seu carrinho, mas não andou. Vendo dúvida em sua expressão, perguntei "Quanto você tirou?"

Ela disse "4". Então Thomas falou "Mais 4, 8!"

Ela olhou para ele e disse "Mais 3!"

Aí ele disse "Então é 7!" E ela percorreu 7 com seu carrinho.

Fonte: JENDREIECK, 2017.

Este episódio mostra que Maria compreendeu a orientação da legenda e sabia que devia realizar a adição de 3 , no entanto não realizou o cálculo. 0 colega Thomas realizou-o para ela.

Quadro 5 - Episódio da segunda partida

Maria jogou o dado e andou 4. Isadora falou "Você estava no Pare! Tem que ler!"

Maria volta com seu carrinho e lê a legenda que diz para somar 3 ao valor retirado. Isadora já pegou o dado e falou "Você já tinha tirado quatro!"

Então eu disse "Só soma mais 3, Maria!"

Ela pensa e responde "7". Então anda 7 com seu carrinho.

Fonte: JENDREIECK (2017).

Este episódio mostra que Maria conseguiu realizar o cálculo de adição, chegando à resposta correta. As ações de Maria mostram o processo da aprendizagem. $\mathrm{O}$ jogo exige um movimento cognitivo intenso e a aprendizagem não ocorre de uma hora para a outra. Nas últimas partidas com o jogo ela já demonstrou o início de uma mudança.

Concordamos com Mrech (2010, p.124) quando afirma que é preciso que o professor também "altere a sua forma de conceber o processo ensinoaprendizagem. Ele não é um processo linear e contínuo que se encaminha numa única direção, mas, sim, multifacetado, apresentando paradas, saltos, transformações bruscas, etc." 
Essa transformação na concepção de ensino-aprendizagem implica numa compreensão de que a resposta sobre um conteúdo ensinado nem sempre pode ser objetiva como "aprendeu" ou "não aprendeu". Pode ser um caminho de idas e vindas, em que o aluno ora usa um procedimento, ora usa outro, ora acerta, ora erra, ora se corrige, ora permanece no erro. É considerar o ensino-aprendizagem como processo de evolução, conforme o conceito apresentado por Guérios (2002), quando diz:

[...] com o termo evoluir queremos nos referir a um caminhar que considera o ir e o vir, o avançar e o retroceder, o errar e o acertar. Acatamos a ideia de evolução como movimento, não significando progresso ou melhoria passível de ser expressa em um resultado absoluto, quantificável e imutável. Significa, antes, caminhar desenvolvendo ou transformando ideias, crescer, expandirse, transformar-se e provocar modificações. (GUÉRIOS, 2002, p. 7).

Maria demonstra que está no processo de aprendizagem, realizando movimentos cognitivos, fazendo tentativas, experimentando, agindo no jogo, desenvolvendo e transformando ideias e que nesse processo seu pensamento está evoluindo.

Quadro 6-Episódio da terceira partida

Maria estava no Pare Roxo. Ela leu a legenda e retirou 5 no dado. Então falou "5, 6, 7, é 7!" Eu perguntei "É 5 mais quanto?"

Maria respondeu "Mais três", então levantou três dedos na mão e contou em voz alta "6, $7,8^{\prime \prime}$.

Em seguida, Thomas falou "5 mais 3 é 8!" E ela andou oito.

Fonte: JENDREIECK, 2017.

Maria realizou a adição, porém iniciou a adição no quinto elemento, contando “5, 6, 7", em vez de iniciar a partir do quinto elemento. Ao ser questionada, Maria refez o cálculo conseguindo corrigir-se sozinha realizando a contagem nos dedos e acertando a resposta.

Grando (2004, p. 81) analisa o erro no jogo e mostra que "surge como fonte de informação estimulando cada um a analisar a sua própria produção compreendendo seus erros e buscando corrigi-los", ou seja, o jogo pode levar o aluno a uma postura diante do erro no jogo diferente da postura que tem nas aulas, pois nelas, muitas vezes, está desmotivado para avaliar e refazer sua produção.

Essa postura diante do erro foi percebida em Maria neste episódio, pois ela erra e, após o questionamento da pesquisadora, se mostra motivada para refazer o cálculo e corrigir seu erro.

A mudança na ação de Maria na resolução do cálculo e na sua motivação para aprender fica ainda mais evidente no episódio a seguir:

Quadro 7 - Episódio da quarta partida 
Maria andou e pegou as cartas estrela. Então contou seu total de cartas e disse "Eu tenho nove! Mais um só!"

Fonte: JENDREIECK (2017).

Os episódios anteriormente apresentados que envolvem o cálculo de Maria demonstram que houve aprendizagem e desenvolvimento da habilidade de realizar cálculos aditivos e multiplicativos.

Quando Maria disse "Deixa eu pensar" ela estava se posicionando de uma maneira como se dissesse para os colegas não dizerem a resposta e darem a ela o tempo de que precisava para realizar o cálculo. Isso demonstra mais segurança por parte da Maria, pois agora ela sabe que pode realizar sozinha o cálculo e acertar a resposta. Ela abre mão da ação de chutar ou de copiar a resposta dos colegas (como foi demonstrado nos trechos do diário e episódios) e opta, com autonomia, por realizar o cálculo.

Esse é um exemplo de como esse jogo criado pode ser gerador de cidadania por meio do desenvolvimento de habilidades, pois o indivíduo que as desenvolve torna-se menos dependente do outro e mais dono de si, agindo no mundo com autonomia e maior liberdade de escolha.

O desenvolvimento da autonomia decorre, entre outras coisas, da possibilidade de decidir, entre opções, em cada situação, aquela que for julgada pelo sujeito a mais adequada. Para tanto o sujeito precisa dispor de um leque amplo de opções que, como vimos, depende de poder defrontar-se com situações diversificadas, e, de preferência, perceptivelmente diversificadas. Só pode ser autônomo aquele que pode escolher. Só pode decidir o melhor aquele que puder escolher entre possíveis de qualidade. Só pode ter opções aquele que formou sua base de conhecimento de forma diversificada. Aquele que não tem como optar tem que ficar com os modelos impostos. (FREIRE, 2005, p.105).

As possibilidades de ação de Maria no jogo se ampliam a partir do momento em que, dominando o cálculo, ela tem a opção de realizá-lo. Ou seja, o conhecimento e a habilidade proporcionam um aumento da liberdade para Maria, pois ela passa a ter mais uma alternativa de escolha: a de realizar o cálculo sozinha, ou, de acordo com o que diz Freire no trecho citado, uma opção possível de qualidade. Quando ela não tinha como optar pela ausência de conhecimento e da habilidade necessária, ficava dependente da resolução dos outros.

Depois de aprender o cálculo e se sentir segura ela pode escolher entre realizar o cálculo, ou chutar, ou esperar que os demais dissessem a resposta. $\mathrm{Na}$ ausência dessa habilidade, suas únicas alternativas eram chutar ou esperar que um colega realize o cálculo para ela.

Compartilhamos com a ideia de liberdade de Morin (1996) quando diz que uma das condições para a existência de liberdade é de natureza interna, dada pelo intelectual, que permite compreender a situação e tomar uma decisão. E tendo em vista que por meio do jogo e da ação didática vinculada a ele, uma criança adquire habilidades que a auxiliam a considerar a situação e ampliam suas possibilidades de escolha, tem-se que o jogo está sendo também instrumento para o exercício da liberdade, da autonomia e da cidadania. 
É importante enfatizar que a aprendizagem não ocorreu apenas pelo jogo, mas também pela ação didática da pesquisadora durante as partidas. Entendemos este jogo como um instrumento para a ação pedagógica, pois ele possibilita o surgimento de situações para o ensino que permitem ampliar o conhecimento escolar do aluno ao mesmo tempo em que permite a vivência de situações educativas para o desenvolvimento de valores.

Concordamos com Moura (2010) que os jogos, assim como outros materiais, são ferramentas para ampliar a ação pedagógica e permitem amplificar e organizar a comunicação, possibilitando aproximar os alunos do conhecimento científico e levando-os a realizar resoluções de situações-problema semelhantes àquelas que os seres humanos enfrentam.

Observamos que a ludicidade inerente ao jogo deixou Maria motivada para aprender e para realizar os cálculos. Isso pode ser percebido também quando ela disse "Deixa eu pensar", demonstrando o desejo de realizar o cálculo e descobrir a resposta sozinha.

Ide (2010) afirma que por meio do jogo e do "clima de liberdade" criado pelo jogo, os alunos ficam mais motivados a usar a inteligência, pois desejam ter sucesso no jogo. Essa motivação os deixa mais ativos mentalmente, auxiliando a superar obstáculos cognitivos e emocionais, estimulando o interesse pela descoberta e pela reflexão. Por isso, os jogos educativos estimulam o desenvolvimento cognitivo e auxiliam no desenvolvimento do cálculo e também da leitura e da escrita.

Além de favorecer a aprendizagem, o jogo também pode proporcionar aos professores uma oportunidade de observar as dificuldades e as dúvidas dos alunos. Esta observação dos professores contribui com o seu planejamento, por exemplo: um professor que perceba uma dificuldade de cálculo durante um jogo poderá planejar outras atividades envolvendo o cálculo em sala de aula de maneira que auxilie o aluno a aprimorar suas habilidades de cálculo também em situações fora do jogo.

Observamos que, mesmo com suas dificuldades no cálculo, Maria venceu o jogo duas vezes. Vencer o jogo é muito importante para uma criança com dificuldades, pois reforça sua autoestima. Seu movimento de superação também é demonstrado nas atividades inicial e final de Maria, na resolução de uma questão que envolvia dobro, cujo enunciado era: Júlia e Alice, ao saírem da escola e andarem 2 quadras na direção Sul chegam em casa. Se elas andarem o dobro, aonde vão chegar?

A resolução de Maria na atividade inicial considerou apenas o valor inicial dado pelo problema, demonstrando que ela não realizou o cálculo do dobro. $\mathrm{Na}$ resolução da mesma questão, na atividade final, feita após 5 partidas do jogo, ela chegou a resposta correta, demonstrando que realizou o cálculo.

As figuras 1 e 2 demonstram a resolução de Maria para esta situaçãoproblema nas atividades inicial e final. 
Figura 1 - Resolução de Maria na questão (d) da atividade inicial

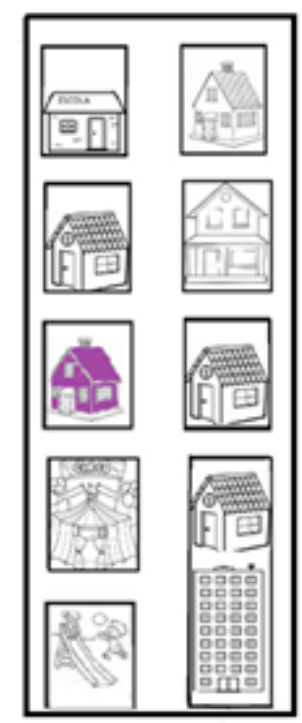

Fonte: JENDREIECK (2017).

Figura 2 - Resolução de Maria na questão (d) da atividade final

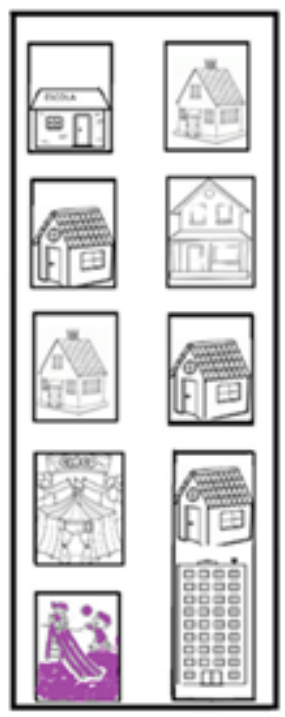

Fonte: JENDREIECK (2017).

\section{CONSIDERAÇÕES FINAIS}

A cidadania foi vivenciada no jogo por meio das ações dos jogadores relativas às emoções, valores, autonomia e liberdade. As emoções estavam presentes durante todo o tempo, demonstradas no prazer pelo jogo, no desejo de continuar jogando e de vencer, na ansiedade por estar próximo de vencer, nas comemorações pela vitória e também na lamentação por ter perdido e pelo final das partidas.

A liberdade foi vivida no jogo por meio das possibilidades de criação, de escolha e de tomada de decisão em cada jogada. Além disso, foi percebido um aumento da liberdade decorrente do aumento do conhecimento e aprimoramento 
das habilidades, pois mais conhecimento e habilidade proporcionam mais opções de escolha e aumento da autonomia. Nas relações entre os participantes foram demonstrados valores como o respeito, a competitividade e a colaboração.

O jogo oportunizou a vivência de valores e de cidadania, pois os jogadores demonstraram respeito às regras e situações de jogo, mesmo quando estas eram uma desvantagem para eles. Também observamos atitudes de respeito aos demais participantes e a colaboração entre eles, mesmo se tratando de um jogo competitivo. Além disso, o jogo é um espaço de criação e liberdade, pois em cada jogada existem diferentes possibilidades para a tomada de decisão.

O jogo é uma espécie de simulação da vida em sociedade, pois têm regras que precisam ser seguidas e, ao mesmo tempo, há várias possibilidades de escolha. Neste jogo, em cada jogada, há vários caminhos que podem ser seguidos. 0 jogo permite criar estratégias diferentes para os objetivos dos jogadores. Sendo assim, o jogo é também um espaço de liberdade de criação e liberdade de escolha.

O jogo desenvolveu autonomia e empoderamento dos sujeitos, uma vez que promovendo aprendizagem e aprimorando habilidades, deu aos participantes ampliação das possibilidades de escolha e da capacidade para julgar as situações, permitindo a tomada de melhores decisões. Tomar decisões envolve julgamento e, como nos diz D'Ambrosio (2002), tomá-las sobre situações inesperadas é um grande desafio na vivência da cidadania:

Cidadania tem tudo a ver com a capacidade de lidar com situações novas.
Lida-se com situações conhecidas e rotineiras a partir de regras que são
memorizadas e obedecidas. Mas o grande desafio está em tomar decisões
sobre situações imprevistas e inesperadas, que hoje são cada vez mais
frequentes. A tomada de decisões exige criatividade e ética. A matemática é
um instrumento importantíssimo para a tomada de decisões, pois apela para
a criatividade. Ao mesmo tempo, a matemática fornece os instrumentos
necessários para uma avaliação das consequências da decisão escolhida. A
essência do comportamento ético resulta do conhecimento das
consequências das decisões que tomamos. (D’AMBROSIO, 2002, p. 3).

Os trechos do diário, os episódios dos vídeos e as atividades inicial e final demonstraram que Maria obteve mudanças nas habilidades de cálculo aditivo e multiplicativo e na compreensão do termo matemático "dobro". Essas aprendizagens foram significativas para a formação humana e cidadã de Maria, pois aumentaram sua liberdade de ação no jogo, pois, sentindo-se mais confiante para realizar cálculos com autonomia, Maria tem a chance de calcular sozinha, deixando de copiar dos colegas ou esperar que eles resolvam para ela.

A superação das dificuldades de cálculo por Maria demonstra que crianças com dificuldades em matemática também podem ter no jogo uma possibilidade interessante de atividade, pois com a ação didática do professor junto ao jogo poderão ficar mais motivadas para a aprendizagem e para a superação de dificuldades. Por fim, conclui-se que o jogo interdisciplinar, objeto desta pesquisa, pode auxiliar professores dos anos iniciais do Ensino Fundamental nas aulas de matemática e de geografia, além de aliar aprendizagem matemática e aprendizagem de valores para o exercício da cidadania, constituindo-se em recurso educativo. 


\title{
The calculation of Maria: contributions of an interdisciplinary game for the development of citizenship
}

\begin{abstract}
The purpose of this article is to present a review of a research that investigated contributions that an interdisciplinary educational game provided for the development of skills of the mathematics and geography subjects of students of the 3rd year of elementary school. The main theoretical references were Grando $(2000,2004)$, Machado $(2001,2006)$ and Moura (1992, 2010). The research developed was qualitative and interventional. The participants were 8 students enrolled in the 3rd year of Elementary School. For the development of the research, an interdisciplinary game was created by the researchers and validated by a team of education professionals. For the data collection, an initial activity was carried out, five games followed by five activities focused on solving problem situations arising from the game and a final activity. Systematic observation was performed in loco with subsequent production of narratives, filming of matches and activities after the game and records of the resolutions of the initial and final activities. For the analysis, a unique method was created for this research, with a triangulation of the instruments. In this article we will present a fraction of the results obtained and their discussions. It is concluded that the game, with its interdisciplinary characteristic, can help teachers in mathematics and geography classes, besides allying mathematical learning to learning values for citizenship, constituting an educational resource.
\end{abstract}

KEYWORDS: Interdisciplinarity. Game. Mathematics teaching. Citizenship and Mathematics. 


\section{REFERÊNCIAS}

ALENCAR D'AMBROSIO, U. Que matemática deve ser aprendida nas escolas hoje? Teleconferência apresentada no Programa PEC - Formação Universitária. Secretaria de Educação do Estado de São Paulo, São Paulo, 2002. Disponível em: $<$ https://drive.google.com/file/d/OB4JIJny - 7paVFQdVY5aVI5YzA/view>. Acesso em: 27 abr. 2017.

DAMIANI, M. F. Sobre pesquisas do tipo intervenção. In: ENDIPE ENCONTRO NACIONAL DE DIDÁTICA E PRÁTICAS DE ENSINO, 16, 2012, Campinas. ALMEIDA, M. I. et al. (Orgs.) Política educacionais e impactos na escola e na sala de aula. Araraquara: Junqueira \&Marin, 2012. Disponível em:

$<$ http://www.infoteca.inf.br/endipe/smarty/templates/arquivos template/uploa d arquivos/acervo/docs/2345b.pdf>. Acesso em: 06 mai. 2017.

FREIRE, J. B. 0 jogo: entre o riso e o choro. 2 ed. Campinas: Autores Associados, 2005.

GRANDO, R. C. O conhecimento matemático e o uso de jogos na sala de Aula. 224 p. Tese (Doutorado) - Faculdade de Educação, Universidade Estadual de Campinas, Campinas: 2000. Disponivel em:

<http://repositorio.unicamp.br/bitstream/REPOSIP/251334/1/Grando ReginaCel ia D.pdf>. Acesso em: 15 jun. 2018.

GRANDO, R. C. O jogo e a matemática no contexto da sala de aula. São Paulo: Paulus, 2004.

GUÉRIOS, E. C. Espaços oficiais e intersticiais da formação docente: histórias de um grupo de professores na área de ciências e matemática. $234 \mathrm{f}$. Tese (Doutorado) - Faculdade De Educação, Universidade Estadual de Campinas, Campinas, 2002. Disponível em:

<http://repositorio.unicamp.br/bitstream/REPOSIP/253667/1/Gu\%3Frios,E.C.pdf >. Acesso em: 14 Ago. 2016.

IDE, S. M. O jogo e o fracasso escolar. In: KISHIMOTO, T.M. (Org.) Jogo, brinquedo, brincadeira e a educação. 13. ed. São Paulo: Cortez, 2010.

JENDREIECK, C. O. Matemática, geografia e cidadania: contribuições de um jogo educativo interdisciplinar para o desenvolvimento de habilidades no 3 o ano do ensino fundamental. 174 f. Dissertação (Mestrado em Educação) - Universidade Federal do Paraná, Curitiba, 2017. 
MORIN, E. A noção de sujeito. In: SCHNITMAN, D. F. (Org.) Novos paradigmas, cultura e subjetividade. Tradução de: RODRIGUES, J. H. Porto Alegre: Artes Médicas, 1996. p. 45-58. Título original: Nuevos paradigmas, cultura y subjetividad.

MOURA, M. O. O jogo e a construção do conhecimento matemático. In: Série Idéias, n. 10, São Paulo: FDE, 1992. p. 45-53. Disponível em:

$<$ http://www.crmariocovas.sp.gov.br/dea a.php?t=020>. Acesso em 02 de novembro de 2016.

MOURA, M. O. A séria busca no jogo do lúdico na matemática. In: KISHIMOTO, T. M. (Org.) Jogo, brinquedo, brincadeira e a educação. 13. ed. São Paulo: Cortez, 2010.

MRECH, L. M. O uso de brinquedos e jogos na intervenção psicopedagógica de crianças com necessidades especiais. In: KISHIMOTO, T. M. (org.) Jogo, brinquedo, brincadeira e a educação. 13. ed. São Paulo: Cortez, 2010.

Recebido: 23 mai. 2018

Aprovado: 23 jul. 2018

DOI: $10.3895 /$ actio.v3n3.8107

Como citar:

JENDREIECK, C. de O.; GUÉRIOS, E. O cálculo de Maria: contribuições de um jogo interdiciplinar para o desenvolvimento da cidadania. ACTIO, Curitiba, v. 3, n. 3, p. 489-505, set./dez. 2018. Disponível em: $<$ https://periodicos.utfpr.edu.br/actio>. Acesso em: XXX

Correspondência:

Céres de Oliveira Jendreieck

Rua Amazonas, 662, ap. 25, Água Verde, Curitiba, Paraná, Brasil.

Direito autoral: Este artigo está licenciado sob os termos da Licença Creative Commons-Atribuição 4.0

Internacional.

(c) (i) 